\title{
Research on Critical Thinking Cultivation and College Chinese Teaching
}

\section{Yuanyuan Chen}

Public teaching department of The Open University of Xuzhou 221006 Xuzhou Jiangsu Province, China

Keywords: critical thinking, Chinese teaching, cultivating

\begin{abstract}
For a long time, students' critical thinking cultivation in college Chinese teaching has been neglected due to many reasons. Currently, based on the requirements to cultivate talents for social development, it is necessary and important to stress the cultivation of students' critical thinking. This thesis tries to combine critical thinking cultivation and college Chinese teaching and the thesis is composed by four parts. Part One makes a short introduction about the current situation of college Chinese teaching and the arising problems caused by the neglecting of critical thinking cultivation. Part Two gives the definition and literature review of critical thinking. Part Three states the necessity of critical thinking cultivation in college Chinese Teaching. Part Four talks about the principles of critical thinking. Part Five discusses practical ways to cultivate critical thinking in Chinese teaching.
\end{abstract}

\section{Introduction}

It is widely accepted that the $21^{\text {st }}$ century is an information era, with knowledge traveling enormously faster in an unprecedented speed. Every day, we are facing huge amount of knowledge. And we begin to realize that even though the internet can provide us with the huge amount of information, the so much information will be a burden for us if we don't have a critical mind towards it and we will even be drowned with all of the knowledge. Therefore, we, especially our students, should have critical thinking and learn to choose and process all the information.

Though we have called for the quality-oriented education for a long time, as the matter of fact, the exam-oriented education is still getting the upper hand in our China. It can be reflected from the test papers: students are still required to choose the only one right answer from the four given choices. In other words, our students are taught to choose the only right answer since entering the primary school and they spend much time memorizing the correct answer without further thinking. Under this mode, the knowledge taught by teachers and gained from all kinds of books is considered completely correct, and teachers and scholars are seen as the unshakable authorities. Students firmly believe that the knowledge they receive is true. Some students even take the tales and rootless theory as useful knowledge. This phenomenon poses big threat to the development of the students and the social and economic development. In this sense, the cultivation of critical thinking becomes more and more important and necessary.

\section{The definition and Literature View of Critical Thinking}

\subsection{The definition of critical thinking}

Critical thinking is the objective analysis of facts to form a judgment. The subject is complex, and several different definitions exist, which generally include the rational, skeptical, unbiased analysis, or evaluation of factual evidence. Critical thinking is self-directed, self-disciplined, self-monitored, and self-corrective thinking.

The list of core critical thinking skills includes observation, interpretation, analysis, inference, evaluation, explanation, and metacognition. According to Reynolds (2011), an individual or group engaged in a strong way of critical thinking gives due consideration to establish for instance: (1) evidence through reality; (2) context skills to isolate the problem from context; (3) relevant criteria for making the judgment well; (4) applicable methods or techniques for forming the judgment; (5) applicable theoretical constructs for understanding the problem and the question at hand. 
What's more, in addition to command strong critical-thinking skills, people should also engage problems and decisions using these critical thinking skills. As a matter of fact, critical thinking demands not only logic but also many other intellectual principles, for example, clarity, credibility, accuracy, precision, relevance, depth, breadth, significance, and fairness and so on.

Critical thinking is not directly connected with solving the problems; it doesn't mean to improve one's own thinking. Exactly speaking, we do not use critical thinking to solve the problems that we meet; instead, we use critical thinking to improve the process of our thinking. It is inward-directed with the intent of maximizing the rationality of the thinker.

\subsection{Literature review}

Socrates was the first person that conveyed critical thinking. He argued, in order to have sound knowledge and insight, one could not only rely on those "authority". He stressed the importance of asking deep questions that probe profoundly into thinking before we accepted ideas as worthy of belief. His method of questioning is now known as "Socratic Questioning" and is the best well-known critical thinking teaching strategy.

Aristotle and subsequent Greek skeptics polished Socrates' teachings strategy to make sure of the true nature of reality beyond the way things appear from a glance.

Richard W. Paul (1994) describes critical thinking as a movement in two "waves". The first "wave" is critical analysis and the second "wave" is critical thinking.

Barry K. Beyer (1995) holds the opinion that critical thinking means making clear, reasoned judgments.

In the past 20 years, the development of critical thinking has been highly valued in western countries. However, China's research in critical thinking is very weak and lags behind.

\section{The necessity of critical thinking cultivation in College Chinese Teaching}

In western countries, critical thinking has become the core skills of modern education. Many countries like UK and US, have proposed specifically the cultivation of critical thinking in their course standards. China, however, is a nation that has been in lack of rational critical thinking. Therefore, cultivation of critical thinking has not attracted enough attention. With the development of society, education in China also calls for reform. And people begin to know the importance and necessity of critical thinking in education.

\subsection{From the perspective of Chinese teaching}

For a long time, especially in the elementary education stage, Chinese course is considered to be the fundamental of other subjects. So, Chinese teaching gradually becomes the process of conveying fundamental knowledge to students. In Chinese teaching, great attention is paid to the scientification of the knowledge and the logical connection between the knowledge points. Teachers often pay special attention to students' comprehension; little attention is paid to the accuracy, correctness and value of the knowledge. What' more, some teachers will on purpose avoid discussing with students about how to evaluate the knowledge to protect his image of "authority".

Though we have earnestly called for the cultivation of innovation for many years, the fact is that the exam-oriented education is still getting the upper hand in our China. Traditional teaching methods are still adopted and students are still required to give the only one absolutely correct answer in the exam. Thus, it is not difficult to realize that students in our country lack of critical thinking and they can't think independently and comprehensively. But we should know clearly that this kind of students cannot keep pace with the faster social and economic development.

\subsection{From the perspective of the cultivation of students' creativity}

In the 21st century, a country's fast and sustainable development in economy will mostly rely on the labors' creativity. To create means that people should be good at discovering the problems and finding the irrational factors from the given fact. This requires that people should adopt critical thinking to treat everything. In this sense, critical thinking is the core part of creativity. Therefore, to 
cultivate creative students, first of all, we should cultivate creative thinking.

Hunt, American scholar, pointed out that the quality of critical thinking will decide the life quality and even the future of the whole world. However, there are obvious problems in Chinese teaching. Let's take the composition writing for example. Our students also make up false words, feelings and stories when writing a composition. Almost all the students write in their compositions that they once helped the disabled or the elder to cross the street, or sending umbrella to the teacher or borrowed erasers from his or her classmates. They make up the same stories happily only because this kind of topics will help them to get a high score. The above phenomenon can be summarized in one sentence, that is, there exists a form in composition writing. And we can easily find out the deep-rooted reasons for this phenomenon. That is because critical thinking doesn't gain enough attention. It is believed to have little connection with the standard exam and the fierce examination. In the long run, students form the habit of listening to, understand and accept the knowledge passively. They hardly think independently and question the knowledge taught by teachers.

\subsection{From the perspective of the attributes of Chinese teaching}

Currently, in our college Chinese teaching, due to the traditional teaching concepts, teachers still pay more attention to knowledge transferring, without giving necessary instructions to students to help them absorb the knowledge critically. In fact, college Chinese Teaching is a course fit for critical thinking cultivation because college students are open-minded and can think actively and deeply. But the problem is that teachers haven't given students enough chance to think, discover, and criticize. Therefore, it is reasonable and practical to cultivate critical thinking in college Chinese teaching.

From what has been mentioned above, it is obvious that to cultivate students' critical thinking is the requirement of students' comprehensive quality and is also the topic that Chinese teaching reform should work at.

\section{Principles of Critical Thinking Cultivation}

Critical thinking cultivation should obey the following principles:

1) Democracy. Critics and democracy are opposite. If we want to cultivate students' critical thinking, a democratic atmosphere is necessary. Only in a democratic and friendly atmosphere do the students dare to adopt a critical attitude.

2) Participation. Students will have few chances to cultivate critical thinking if the teaching was conducted in the traditional way, that is, the class is dominated by teachers. To cultivate critical thinking, students should be encouraged to participate all kinds of activities such as discussion, debate, and questioning and so on.

3) Subjectivities. It is commonly accepted that students are the subjects in the process of learning. But in class, teachers still play the dominant part. This situation is even worse in remote areas. The evaluation of the class is decided by the knowledge and performance of the teacher, with little attention paid to the activeness and enthusiasm of the students. Under such teaching mode, students are getting used to relying their teacher for correct answer, let alone cultivating critical thinking.

4) Objectiveness. Critical thinking should be cultivated reasonably and rationally. An objective attitude should be adopted toward the knowledge. In other words, we should not criticize just for criticizing.

\section{Ways to Cultivate Critical Thinking in College Chinese Teaching}

\subsection{The preparation of the textbooks}

As the main carrier of the teaching materials, the textbook should create conditions to support the cultivation of critical thinking.

For one thing, the Chinese textbooks should combine students' life and learning experience and shouldn't break away from it. For another thing, besides giving specific notes to the passages, the 
textbooks should also include metaphor and various descriptions to make sure that it can be practically used. What is more, the textbook should be flexible and leave enough space for change and complement so that the teacher could use the textbook accordingly. Only in this way could it provide enough opportunity for students and teachers to criticize and explain.

In a word, as the main medium of Chinese teaching, the main aim of the Chinese textbooks is to serve Chinese teaching and to serve the students. Ultimately, it is the students' duty to comprehend, criticize and absorb the textbooks. And by doing this, the students can acquire knowledge and improve the overall ability.

\subsection{For teachers}

Teachers are the organizer of the class. In order to cultivate students' critical thinking, the teachers should create a fair, open, and easy-going atmosphere and encourage students to question, think and criticize. The dialogue or discussion between teachers and students should be equal and teachers should give necessary guidance. Therefore, it raises higher requirement for the quality of the teachers.

In my opinion, the teachers should be qualified in the following aspects in order to carry out critical thinking teaching:

(1) Teachers should have the concept of the critical thinking cultivation. Teachers should consider critical thinking teaching necessary, interesting and valuable. Teachers should have an open mind and can make use of the textbooks creatively. Teachers should also give necessary guidance to students in the process of critical thinking cultivation.

(2) Teachers should have the knowledge of the critical thinking cultivation. First, teachers should have a good command of the knowledge in the textbook; second, teachers should make use of proper teaching approach to carry out teaching; last but not least, teachers should know some tactics that can smooth the teaching process.

(3) Teachers should have the ability to carry out of the critical thinking cultivation. In order to carry out critical thinking teacher, the teacher himself should firstly be a critical thinker. The teachers should thinking critically and question tactically; at the same time, the teacher should also make use of the textbooks creatively and adopt proper teaching strategies.

As a matter of fact, teachers' critical thinking is the most important part for the cultivation of the students' critical thinking. It is hard to imagine that teachers without critical thinking could cultivate students' critical thinking in the process of teaching. As far as I am concerned, teachers could improve critical thinking in the following aspects:

First, teachers should have basic knowledge about logic thinking and make himself armed with relevant theory. Second, teachers should use critical thinking in the process of teaching, research and even daily life so that he can form good habit of critical thinking. Thirdly, teachers should set a good example for the students by using critical thinking in the process of teaching process, for example, teachers may thinking actively and try to explore the mistakes in the textbook and then amend it. Fourthly, teachers should have a deep research into the Chinese course and find the breakthrough point so that teachers can find out the best plan for carrying out critical thinking teaching. Fifthly, teachers should continuously absorb up-to-date achievement home and abroad to improve themselves; sixthly, teachers should have the ability of self-examination; that is to say, teachers should form the habit of self check and rethink profoundly. Only in this way, could the teachers get improvement quickly.

Then, how to effectively guide the students to think critically? In my opinion, the teacher should make good use of questions. Generally, the questions should have the following features:

First, the questions should be open. In other words, the questions should not have a standard correct answer.

Second, the question should be transferrable. That is to say, the questions should have enough space for students to explore.

Thirdly, the questions should make students have his own understanding and thinking.

Fourthly, the questions should be comparative. The students should firstly make a comparison 
thoroughly in order to answer the questions. By doing this, the students will learn to think comprehensively and deeply.

\subsection{For students}

Students are the center of the class. In order to better the process of critical thinking teaching, students should possess the following conditions.

The first condition is that the students should love learning and love Chinese. We all know that interest is the best teacher. If the students have a strong interest in Chinese course, he will surely be active in taking part in the teaching activities. He would like to follow the teachers in class and therefore, his critical thinking would be cultivated and strengthened in the process of learning under the teachers' instruction.

The second condition is that the students should command a certain amount of knowledge to make sure that he can use critical thinking to have an all round thinking and analysis. It is surely impossible for students to cultivate critical thinking if he doesn't possess the relevant knowledge at all because he knows nothing at all, let alone using critical thinking to criticize and try to give more reasonable answer.

The third condition is that the students should have good virtues. It is widely accepted that intelligence is more important than knowledge and; quality is more important than intelligence, and consciousness is more important that quality. A critical thinker ought to have a responsibility towards his country, society and the human kind. For students, they should connect his own fate with the fate of the country and the people tightly. He should have the courage to march forward bravely to be in pursuit of truth and knowledge. Critical thinking requires that the students ought to possess the courage of marching forward boldly and brave any difficulties and jeers.

In a word, the cultivation of critical thinking is necessary and urgent in college Chinese teaching. Only by we cultivating more and more critical thinker in college Chinese teaching, could Chinese course plays its role in shaping a person. In the long run, if the students become critical thinker, they would likely be an all round man. And that is the very aim of education. They will think deeply and critically. They would probably find out the mistakes and then correct them. They will get themselves easily adapted to the fast changing society. And most importantly, they will make more contributions to the development of the whole society and human kind.

\section{References}

[1] Edward M. Glaser. "Defining Critical Thinking". The International Center for the Assessment of Higher Order Thinking (ICAT, US)/Critical Thinking Community. Retrieved 2017-03-22.

[2] Mulnix, J. W. (2010). "Thinking critically about critical thinking". Educational Philosophy and Theory. 44: 471.

[3] Carmichael, Kirby; letter to Olivetti, Laguna Salada Union School District, May 1997.

[4] Walters, Kerry (1994). Re-Thinking Reason. Albany: State University of New York Press.

[5] Reynolds, Martin (2011). Critical thinking and systems thinking: towards a critical literacy for systems thinking in practice. In: Horvath, Christopher P. and Forte, James M. eds. Critical Thinking. New York: Nova Science Publishers, pp. 37-68.

[6] Edward M. Glaser (1941). An Experiment in the Development of Critical Thinking. New York, Bureau of Publications, Teachers College, Colu mbia University. ISBN 0-404-55843-7. 